\title{
Two unusual cases of external rotator muscle pathology producing hip pain
}

\author{
Author: \\ Graeme Thompson ${ }^{1}$ \\ Affiliation: \\ ${ }^{1}$ Morton and Partners, Cape \\ Town, South Africa \\ Correspondence to: \\ Graeme Thompson \\ Email: \\ gt@morton.co.za

\section{Postal address:} \\ 20A Brommaert Avenue, \\ Constantia 7806, Cape Town, \\ South Africa \\ Dates: \\ Received: 06 Oct. 2014 \\ Accepted: 16 Feb. 2015 \\ Published: 08 May 2015 \\ How to cite this article: \\ Thompson, G. Two \\ unusual cases of external \\ rotator muscle pathology \\ producing hip pain. S Afr J \\ Rad. 2015;19(1); Art. \#740, \\ 3 pages. http://dx.doi. \\ org/10.4102/sajr.v19i1.740 \\ Copyright: \\ C 2015. The Authors. \\ Licensee: AOSIS \\ OpenJournals. This work is \\ licensed under the Creative \\ Commons Attribution \\ License.
}

Read online:
Two unusual cases of inflammation of the external rotator muscles of the hip are presented. In each case, the patient presented with acute hip pain. The diagnoses of acute calcific periarthritis involving the gluteus medius muscle, and pyomyositis of the obturator internus muscle secondary to a perianal fistula, were made with the aid of diagnostic imaging and histology. The importance of reviewing the pelvic viscera is highlighted.

\section{Introduction}

Requests for imaging of hip pain and extraspinal sciatica are increasingly common, particularly in the setting of femoro-acetabular impingement and the burgeoning field of hip arthroscopy. The two cases discussed represent uncommon causes of hip pain with similar imaging features, stressing the need for vigilance beyond the acetabular labrum.

\section{Case presentations}

\section{Case 1}

A 46-year-old woman presented with a 6-month history of left hip stiffness and a 1-week history of severe pain. She was apyrexial with a normal erythrocyte sedimentation rate (ESR) and white cell count. The initial pelvic radiograph (Figure 1) demonstrated a focus of globular calcification above the left greater trochanter. An axial proton density fat saturation (PDFS) magnetic resonance image (MRI) (Figure 2) showed enlargement of her left gluteus medius muscle, with diffuse oedema. In addition, there were globular foci of calcium within the muscle and connective tissue (Figure 3). A provisional diagnosis was made of acute calcific periarthritis that was presumed to have arisen as a complication of long-standing gluteus medius calcific tendonitis. However, owing to the extent of the abnormal signal and unusual imaging appearance, the possibility of a synovial sarcoma could not be excluded, and an open biopsy was performed that confirmed an acute inflammatory process with calcification and no sign of malignancy. The patient was treated conservatively and her pain resolved completely with resolution of the residual calcification.

\section{Case 2}

A 57-year-old man presented with pain in the left leg. Clinical examination suggested a lumbar disc lesion, but the MRI of the lumbar spine was normal. An MRI of the left hip was requested. The initial large field of view coronal images with fat suppression revealed marked oedema of the obturator internus and gemelli muscles on the left (Figure 4) with a loculated fluid component (Figure 5) corresponding to the site and 'boomerang' shape of the obturator internus bursa. ${ }^{1}$ Review of the pelvic viscera revealed an anorectal fistula on the left (Figure 6), containing fluid and extending to both the skin of the natal cleft and the left scrotum. The ESR was subsequently reported raised $(80 \mathrm{~mm} / \mathrm{hr})$. Antibiotic therapy was initiated, to which the patient responded. A dedicated MRI fistula study was performed that did not demonstrate a direct connection to the obturator internus muscle but did show abnormal signal related to the levator ani and the precoccygeal soft-tissue. The patient was referred to a general surgeon for further treatment.

\section{Discussion}

Acute calcific periarthritis is a diagnostic subset of hydroxyapatite deposition disease in which the clinical presentation is acute and associated with periarticular calcification that is either in a tendon, bursa or joint capsule. ${ }^{2}$ Most cases are idiopathic, although the calcification may also be secondary to systemic disease such as hypervitaminosis D and renal failure. The most common site of hydroxyapatite deposition is the rotator cuff of the shoulder, accounting for $69 \%{ }^{3}$ of cases and commonly termed calcific tendonitis. Speed et al. ${ }^{4}$ described four stages of calcific tendonitis. In the third or 'resorptive' phase, calcium extrudes into the surrounding tissues 


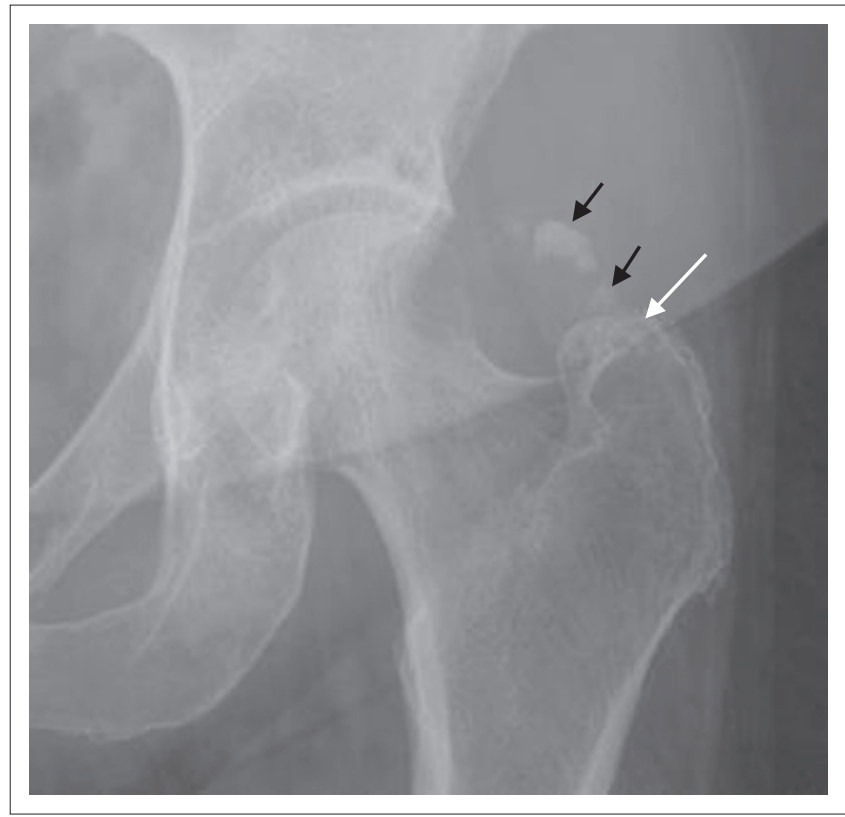

FIGURE 1: Anteroposterior radiograph of the left hip. Globular, poorly defined calcific deposits (short black arrows) above the greater trochanter (long white arrow) - a characteristic site for gluteus medius calcific tendonitis.

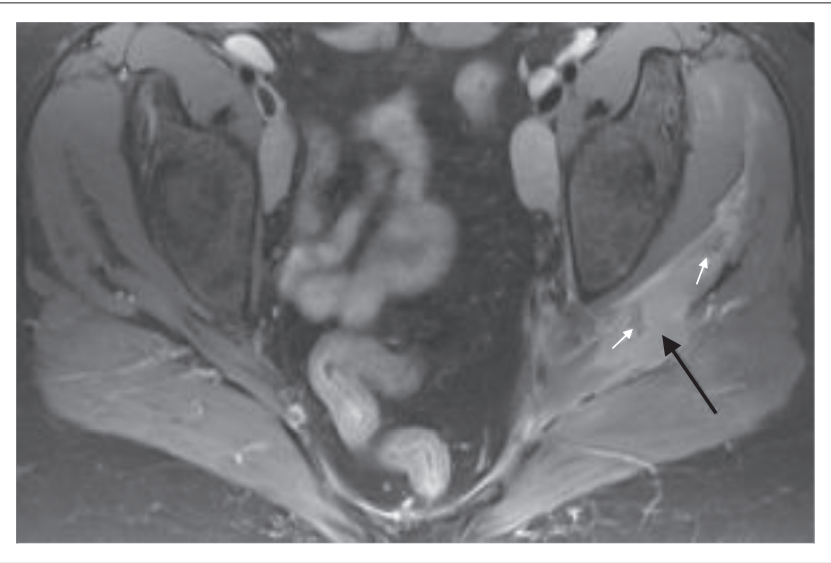

FIGURE 2: Axial proton density fat saturation (PDFS) image of the pelvis. Mass-like enlargement and hyperintensity of the gluteus medius muscle (long black arrow) with amorphous hypointense calcium deposits (short white arrows). Reactive external iliac adenopathy is also evident.

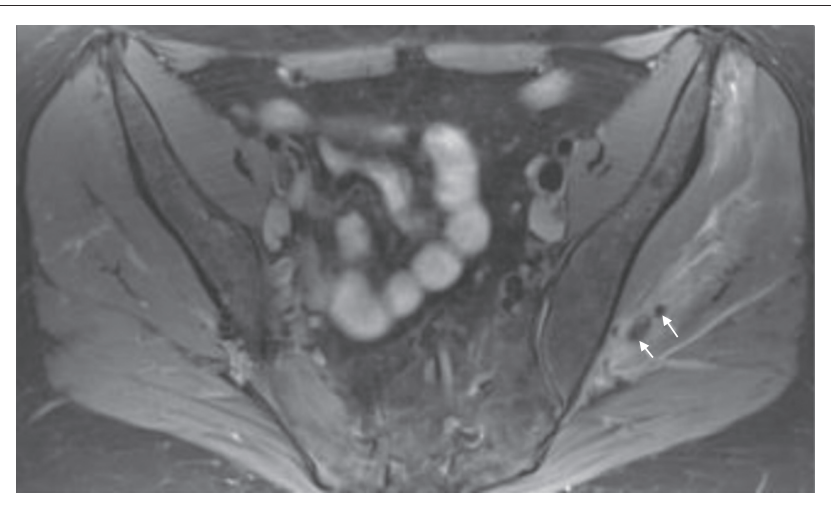

FIGURE 3: Axial proton density fat saturation (PDFS) image of the pelvis. Defined globular calcium deposits are evident.

with resultant severe pain and limitation of movement; this may be associated with erythema and local warmth, resulting in confusion with infective causes. ${ }^{5}$ The diagnosis

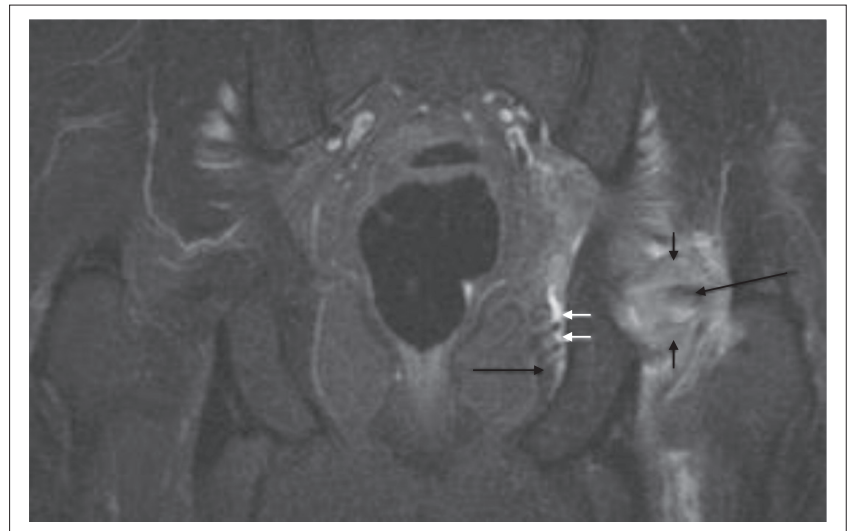

FIGURE 4: Coronal short T1 inversion recovery (STIR) of the pelvis. Oedema of the extrapelvic obturator internus (long black arrow) and gemelli muscles (short black arrows). The medial intrapelvic portion of the obturator internus bursa (short white arrows) and muscle (medium black arrow) are shown.

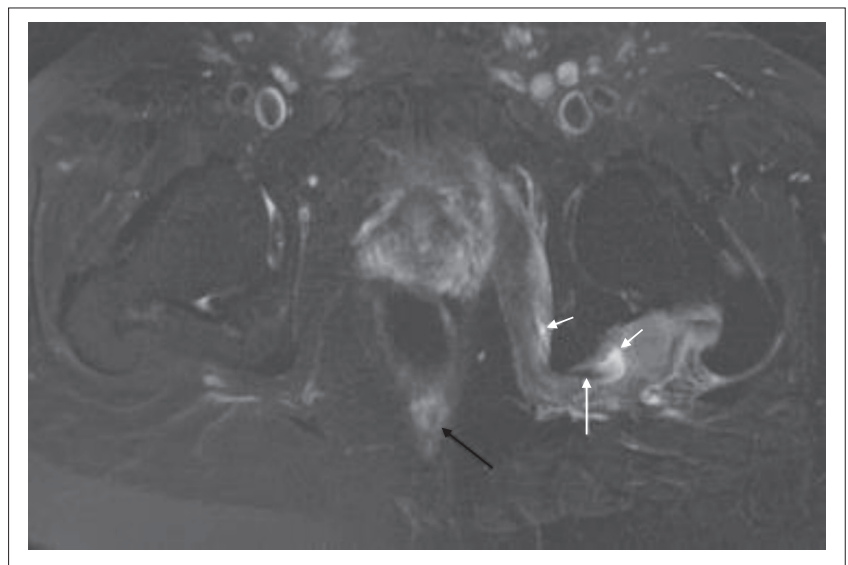

FIGURE 5: Axial T2FS of the pelvis. Fluid in the obturator internus bursa with a 'boomerang' configuration around the iliac spine (short white arrows). The obturator internus tendon (long white arrow) and pre-coccygeal signal (long black arrow) are also shown.

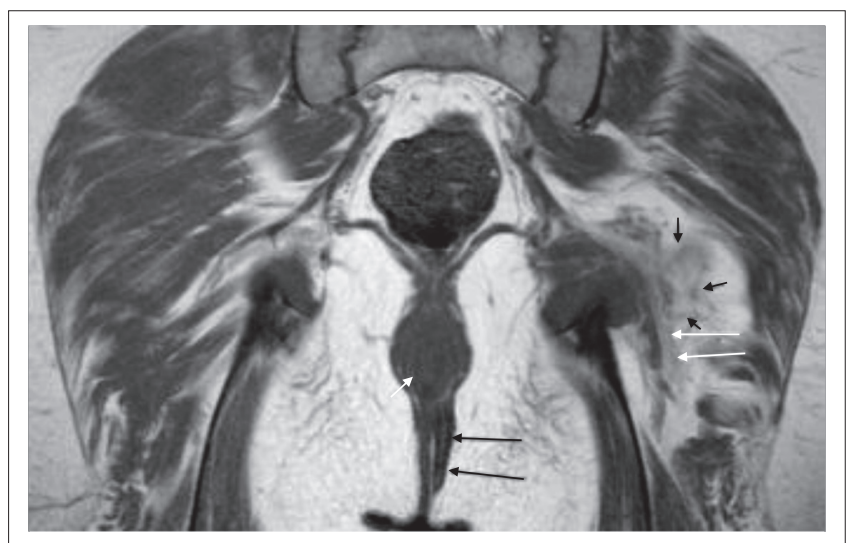

FIGURE 6: Coronal T1W image. A perianal fistula (long black arrows) extending vertically from the anus (short white arrow) to the natal cleft. The vertical course of the sciatic nerve (long white arrows) is closely related to inflammatory changes in the adjacent fat (short black arrows) which may account for the presentation mimicking sciatica.

relies on the identification of characteristic calcification. Radiographs demonstrate globular, poorly defined calcific deposits, although occasionally they may be small and well defined and therefore overlooked as dystrophic deposits or ossicles, which are common around the hip. Extrusion of calcium into an adjacent bursa or soft-tissue is well shown 
on ultrasound or MRI. The resultant severe inflammatory reaction is demonstrated on MRI as bursal, muscular or softtissue oedema and enhancement. The differential diagnoses besides infection include trauma or synovial sarcoma, the latter commonly peri-articular and containing calcification. ${ }^{6}$ Following the acute phase, many patients will have symptoms that resolve spontaneously, although often there is some residual limitation of movement.

Pyomyositis of the obturator internus muscle is an unusual condition that has been described in children, ${ }^{7}$ with the predominant organism being Staphylococcus aureus and the mechanism, haematogenous seeding. The lesser sciatic foramen, through which the obturator internus passes, is a known pathway for pelvic infection to spread externally. ${ }^{8}$ In the present case, the pyomyositis was associated with fluid distention of the obturator internus bursa which lies between the tendon and the cartilage-covered posterior surface of the ischium ${ }^{9}$ and could be mistaken for a muscle abscess. Obturator internus muscle and bursal infection respond well to antibiotics and MRI may prevent surgery. ${ }^{7}$ An important clinical differential diagnosis in the setting of pain and fever is septic arthritis of the hip joint. The imaging differential includes trauma, neoplasia and acute calcific peri-arthritis discussed above.

\section{Conclusion}

The present two cases highlight the importance of applying a large field of view fat-suppressed sequence to evaluate the whole pelvis, including the viscera, when imaging the hip. The author utilises a coronal intermediate weighted sequence with fat saturation; however, short $\mathrm{T} 1$ inversion recovery (STIR) may also be utilised. It is also prudent to evaluate the pelvis MRI in conjuction with a plain radiograph of the pelvis because the former is relatively insensitive to the detection of calcification. That calcification is common around the greater trochanter should not blind one to its unusual acute presentations.

\section{Competing interests}

The author declares that he has no financial or personal relationship(s) that may have inappropriately influenced him in writing this article.

\section{References}

1. Hwang JY, Lee SW, Kim JO. MR imaging features of obturator internus bursa of the hip. Korean J Radiol. 2008;9:375-378. http://dx.doi.org/10.3348/kjr.2008.9.4.375

2. Hayes CW, Conway WF. Calcium hydroxyapatite deposition disease. Radiographics. 1990;10:1031-1048. http://dx.doi.org/10.1148/radiographics.10.6.2175444

3. Gondos B. Observations on periarthritis calcarea. AJR. 1957;77:93-108

4. Speed CA, Hazleman BL. Calcific tendinitis of the shoulder. N Engl J Med. 1999;340:1582-1584. http://dx.doi.org/10.1056/NEJM199905203402011

5. Selby $\mathrm{CL}$. Acute calcific tendinitis of the hand: An infrequently recognized and frequently misdiagnosed form of periarthritis. Arthritis Rheum. 1984;27:337-340. http://dx.doi.org/10.1002/art.1780270314

6. Murphey MD, Gibson MS, Jennings BT, Crespo-Rodríguez AM, Fanburg-Smith J, Gajewski DA. From the archives of the AFIP: Imaging of synovial sarcoma with radiologic-pathologic correlation. Radiographics. 2006:26:1543-1565. http://dx. doi.org/10.1148/rg.265065084

7. Viani RM, Bromberg K, Bradley JS. Obturator internus muscle abscess in children Report of seven cases and review. Clin Infect Dis. 1999;28:117-122. http://dx.doi. org/10.1086/515080

8. Cher HT, Raghunandan V, Piyaporn B. Pathways of extrapelvic spread of pelvic disease: Imaging findings. Radiographics. 2011;31:117-133. http://dx.doi. org/10.1148/rg.311105050

9. Williams A, Newell RL. Pelvic girdle, gluteal region and hip joint. In: Standring $S$, editor. Gray's Anatomy. 39th ed. Philadelphia: Elsevier, 2005; p. 1447-1448. 